\title{
ESTUDO DE CASO: ASPECTOS SOCIOAMBIENTAIS DA PEQUENA CENTRAL HIDRELÉTRICA (PCH)-QUELUZ-SP, NA BACIA DO RIO PARAIBA DO SUL
}

\author{
Giovano Candiani ${ }^{1}$ \\ Claudio Luis de Camargo Penteado \\ Elisângela Cristina Cendretti ${ }^{3}$ \\ Eliane Melo Dos Santos ${ }^{4}$ \\ Ana Elisa Chicarino Biondi ${ }^{5}$
}

\begin{abstract}
Resumo: A geração de energia elétrica é sempre uma atividade impactante do ponto de vista social e ambiental. Seja esta energia gerada por grandes ou pequenos empreendimentos, sempre ocorrerão impactos às comunidades locais, mesmo que em duração e intensidade diferentes. O presente artigo faz uma avaliação dos aspectos socioambientais da instalação de uma pequena central hidrelétrica, a PCH-Queluz-SP, na bacia do rio Paraíba do Sul. No RAP da PCH-Queluz é possível dizer que faltam informações e a participação pública e popular no processo de licenciamento é restrita e pouco eficaz, não ocorrendo presença efetiva da população na tomada das decisões. A maioria da população entrevistada é a favor da construção da PCH-Queluz, porém, grande parte dos entrevistados não conhece o empreendimento. Da maneira como é conduzido o licenciamento ambiental, fica a percepção de que muitas decisões são políticas e os aspectos técnicos são negligenciados.
\end{abstract}

Palavras-chave: Sociedade; Meio Ambiente; Pequena Central Hidrelétrica; Licenciamento ambiental; Avaliação de impacto ambiental.

\section{A CASE STUDY ON THE SOCIO-ENVIRONMENTAL ASPECTS OF THE QUELUZ SMALL HYDROELECTRIC PLANT IN THE RIO PARAIBA DO SUL RIVER BASIN.}

\begin{abstract}
The generation of electricity is an activity that causes social and environmental impacts. This article evaluates the socio-environmental impacts of the construction of a small hydroelectric plant (SHP) in Queluz, São Paulo, Brazil, in the Paraiba do Sul River Basin.The Preliminary Environmental Report lacks information, and participation of the affected population in the licensing and decision making processes was restricted and ineffective. Most of the population favored the construction of the Queluz Small Hydroelectric center. However, we found that the local community was not familiarized with the negatives impacts associated to this enterprise. The form that the environmental licensing of the Queluz SHP was carried out corroborates the perception that many decisions surrounding the approval of this plant were political while technical aspects were neglected. Finally, we suggest that the licensing of SHPs should be analyzed in the same way as large ones because of their impacts local and regional communities.
\end{abstract}

\footnotetext{
${ }^{1}$ Analista Ambiental - QSMA - Essencis S.A. Ecólogo (Unesp). Doutor em Energia - Universidade Federal do ABC, UFABC, Centro de Engenharia, Modelagem e Ciências Sociais Aplicadas, Pós-Graduação em Energia. E-mail: gcandiani@essencis.com.br

${ }^{2}$ Graduação em Ciências Sociais pela Universidade de São Paulo. Mestrado em Ciências Sociais pela Pontifícia Universidade Católica de São Paulo. Doutorado em Ciências Sociais pela Pontifícia Universidade Católica de São Paulo. Professor adjunto da Universidade Federal do ABC. E-mail: claudio.penteado@ufabc.edu.br

${ }^{3}$ Engenheira Agrônoma ,Universidade Federal Rural do Rio de Janeiro, UFRRJ. Pós-Graduação em Educação Ambiental - FIC, Cruzeiro-SP. Prefeitura Municipal de Queluz-SP. E-mail: eccendretti@hotmail.com

${ }^{4}$ Bióloga, Pós-Graduação em Educação Ambiental - FIC, Cruzeiro-SP. E-mail: elianemsantos2006@gmail.com

${ }^{5}$ Bióloga, Pós-Graduação em Educação Ambiental - FIC, Cruzeiro-SP. E-mail: anaelisac14@gmail.com

DOI: 10.7154/RDG.2013.0025.0006
} 
Keywords: society; environment; small hydroelectric center; environmental licensing; environmental impact assessment.

\section{INTRODUÇÃO}

No Brasil, a hidreletricidade tem sido apontada como uma fonte de suprimento energético prioritário, já que o uso dos recursos hídricos para a geração de eletricidade sempre esteve associado à ideia de sustentabilidade (BERMANN, 2007; VAINER, 2007).

Entretanto, o caráter "sustentável" atribuído à hidreletricidade necessita de uma maior análise, pois sua expansão encontra muitos problemas, principalmente porque seu maior potencial está localizado na Região Amazônica, onde existem questões sociais e ambientais complexas. Nas bacias dos Rios Paraná e Uruguai, o potencial hidrelétrico também é significativo, porém são áreas intensamente ocupadas por populações. Em relação às demais bacias hidrográficas no Brasil, existem restrições quanto à disponibilidade hídrica (BERMANN, 2007).

Os empreendimentos hidrelétricos têm se mostrado, na verdade, insustentáveis do ponto de vista ambiental, acarretando problemas ambientais como: alteração do regime hidrológico, comprometimento da qualidade das águas, assoreamento dos reservatórios, emissão de gases de efeito estufa, perda de biodiversidade, problemas de saúde pública e dificuldades para assegurar o uso múltiplo das águas (FILHO et al., 2008; BORGES; MEIRA, 2009). Em relação aos aspectos sociais, destacam-se os impactos sobre as populações ribeirinhas afetadas pelas obras, como sua expulsão da terra e a eliminação do seu modo de vida, baseado na subsistência, por meio da pesca e da lavoura. A insuficiência desta prática é histórica, tornando este modelo de desenvolvimento socialmente injusto e ambientalmente irresponsável (BERMANN, 2007; VAINER, 2007).

Na construção das hidrelétricas, os conflitos socioambientais são inevitáveis, uma vez que envolvem disputas entre diferentes grupos sociais pela apropriação do espaço e de seus recursos (LITTLE, 2001). Enquanto os empreendedores buscam amenizar esses conflitos apoiando-se, sobretudo, em critérios econômicos, seguindo pressupostos de uma racionalidade econômica (cf. Leff, 2007), as partes interessadas (populações atingidas, ambientalistas, movimentos sociais, etc.) evidenciam os conflitos mostrando que nestas obras não são considerados, a contento, os aspectos socias e ambientais. Para os orgãos governamentais, ocorrem disputas internas, pois os setores ligados ao meio ambiente 
defendem a pauta e os interesses dessa área, enquanto para os órgãos de planejamento a obra tem importância estratégica para a política de crescimento do país. Os conflitos, decorrentes das disputas entre os grupos interessados, realçam a dimensão política do processo de construção de uma usina hidrelétrica, na qual os atores buscam interferir na defesa de suas posições e interesses, levando a necessidade de negociação envolvendo os segmentos da sociedade civil organizada, Estado e mercado.

Nesse processo de conflitos, um ponto crítico é a participação da população atingida no processo de tomada de decisão, dominado pelos atores institucionais, como advoga a corrente neoinstitucionalista (FREY, 2000). Quase sempre esta participação é limitada a desenhos institucionais de participação (fóruns, audiências, etc) dominados pelos agentes envolvidos, que possuem maior capacidade de organização e articulação.

Como todo empreendimento relacionado à produção de energia elétrica é impactante do ponto de visto social e ambiental e, portanto, tanto as hidrelétricas de grande porte como as pequenas centrais hidrelétricas ( $\mathrm{PCHs}$ ) causam muitos impactos negativos ao meio ambiente e às populações, é importante que as $\mathrm{PCH}$ sejam avaliadas da mesma maneira que os grandes empreendimentos (BARBOSA; DUPAS, 2008; CENDRETTI; SANTOS; BIONDI, 2009). No caso das PCHs, embora estes impactos sejam em escala menor, não significa que sejam menos importantes e que não necessitam de acompanhamento (BORGES; MEIRA, 2009).

A discussão, então, é em relação à significância desses impactos, considerando a intensidade e a duração e, principalmente, a eficiência das medidas de controle e compensação socioambientais apresentadas pelo empreendedor de uma obra (CARVALHO E ALBUQUERQUE, 2006; GOLDEMBERG; LUCON, 2007; FILHO et al., 2008).

Historicamente, as PCHs foram fundamentais para o desenvolvimento industrial e a urbanização no interior do Estado de São Paulo. Os primeiros registros históricos da hidroeletricidade no Brasil são dos últimos anos do Império, quando o crescimento das exportações do país, principalmente de café, impulsionaram o desenvolvimento (ROLIM, 2009). De acordo com Rolim (2009), as primeiras hidrelétricas eram pequenas usinas, destinadas a usos privados. A concentração dessas usinas na região sudeste, principalmente no interior do Estado de São Paulo, foi fundamental para a criação dos primeiros sistemas elétricos brasileiros.

A primeira usina hidrelétrica no país começou a operar em 1883, no município de Diamantina, no Estado de Minas Gerais. Esta energia produzida era transportada por uma 
linha de transmissão de $2 \mathrm{~km}$ e utilizada na mineração Santa Maria, para extração de diamantes (ERENO, 2009). Ereno (2009) salienta que esse processo teve uma rápida expansão no período de 1920 a 1930, quando o número de PCHs passou de 186 para 519 e a potência de 310 para 655 MW. Porém, a partir de 1960, com a construção das grandes hidrelétricas, as PCHs entraram em um período de declínio.

No início da década de 1980, praticamente todas as PCHs estavam desativadas. Somente no final da década de 1990, com a criação da Agência Nacional de Energia Elétrica (ANEEL), ocorreu uma reestruturação do mercado energético brasileiro, principalmente pelas negociações de consumo no mercado interno e isenções nas tarifas de transmissão, que foram fundamentais para a retomada na expansão das pequenas centrais hidrelétricas (ERENO, 2009).

A partir desse período, as políticas de investimento assumiram um posicionamento de inovação tecnológica e sustentabilidade. Consequentemente, os incentivos focaram na diversificação da matriz energética, destacando-se, por exemplo, o Programa de Incentivo às Fontes Alternativas de Energia Elétrica (PROINFA). Com a criação do PROINFA, foi possível aumentar a participação das fontes renováveis na matriz energética brasileira, e isto serviu para consolidar as pequenas centrais hidrelétricas no mercado.

O termo PCH apareceu em 1982, no Manual de Pequenas Centrais, publicado pelo Ministério de Minas e Energia, com o estabelecimento do Programa Nacional de PCH. Nele, definiu-se $\mathrm{PCH}$ como os aproveitamentos hidrelétricos que apresentam os seguintes critérios: operação a fio d'água ou no máximo com reservatório de regularização diária, barragens e vertedouros com altura máxima de até 10 metros, não utilização de túneis, vazão turbinável de no máximo $20 \mathrm{~m}^{3} / \mathrm{seg}$. e unidades geradoras com potência de no máximo $30 \mathrm{MW}$ (ANEEL, 2012).

A inserção das PCHs no Brasil sempre esteve condicionada ao fornecimento de energia para os locais próximos à queda d'água. O setor de energia elétrica no Brasil, regulamentado até então pelo Estado, manifestava que as $\mathrm{PCH}$ não eram competitivas comparadas às grandes hidrelétricas (LEÃO, 2008).

Mas, com a reestruturação do setor de energia no Brasil, as PCHs tornaram-se interessantes pelos seus inúmeros benefícios, quando comparadas às grandes hidrelétricas, como: facilidade de implantação/operação e menor impacto ambiental e social (ANDRADE, 2006). Sob o ponto de vista socioambiental, no entanto, as PCHs devem ser concebidas com os 
mesmos cuidados observados nos grandes empreendimentos hidrelétricos. Borges e Meira (2009) comentam que uma PCH pode causar menor impacto do que uma grande central hidrelétrica desde que seja realizada uma análise detalhada dos aspectos socioambientais de uma determinada região. Na história recente das $\mathrm{PCHs}$, os exemplos com grandes impactos não são poucos.

Atualmente, no Brasil, existem 402 PCHs em operação, com capacidade de geração de 4.200 MW, cerca de 3\% do total de energia produzida no Brasil (ANEEL, 2012). A maioria das pequenas centrais hidrelétricas localiza-se nas Regiões Sul e Sudeste, nas bacias do Paraná e do Atlântico Sudeste, áreas próximas a grandes centros consumidores de energia elétrica.

As $\mathrm{PCH}$ representam, atualmente, uma fonte relativamente rápida e eficiente de promover a geração de energia elétrica, considerando a descentralização da produção e a diminuição de perdas nos sistemas de transmissão. Todavia, as pequenas centrais hidrelétricas precisam de atenção da sociedade, pois podem se tornar passivos ambientais de natureza significativa se não forem avaliadas corretamente do ponto de vista socioambiental. O agravante é que essas são dispensadas de estudos ambientais mais complexos, como um EIA-Rima, e licenciadas somente por meio de um RAP (Relatório Ambiental Preliminar), que, na maioria dos casos, não aponta todos os impactos ambientais e sociais adequadamente, condição que acaba representando riscos ambientais para um rio ou mesmo uma bacia hidrográfica (ZHOURI; OLIVEIRA, 2007; SILVA NETO, 2008; BORGES; MEIRA, 2009).

Um licenciamento ambiental mais simples das PCHs deve ser visto com cautela, pois um conjunto de pequenas hidrelétricas, em uma mesma bacia hidrográfica, pode causar danos significativos comparáveis aos das grandes hidrelétricas. Este é o caso da PCH-Queluz, localizada na bacia do rio Paraíba do Sul, que se encontra numa região já bastante impactada pela densa ocupação urbana e industrial e, sistematicamente, vem gerando conflitos entre os governos de São Paulo e Rio de Janeiro. As possibilidades de novas instalações de PCHs, na área paulista da bacia hidrográfica, vêm gerando impactos do lado carioca da bacia.

Nesse contexto, o presente artigo busca apresentar e discutir os aspectos socioambientais impactos sobre o meio ambiente (fauna, flora, recursos hídricos e biodiversidade), impacto sobre a vida dos moradores (lazer, emprego, violência, etc.), sobre a economia local, tráfego regional e na demanda de energia - relacionados a percepção da população atingida na 
instalação desta pequena central hidrelétrica, a PCH-Queluz-SP, na bacia do rio Paraíba do Sul.

\section{Legislação ambiental e os impactos da produção de energia elétrica}

A legislação ambiental foi regulamentada pela Constituição Federal de 1988. Entretanto, já em 1981, a Lei Federal 6.938, conhecida como Política Nacional do Meio Ambiente estabelecera o conceito de responsabilidade objetiva, ficando o causador do dano ambiental responsável por sua correção, independentemente de ter ou não culpa.

Para a implantação de um novo empreendimento ou expansão de um já existente, é necessário requerer as licenças por meio de um processo de licenciamento ambiental. 0 processo é composto por três etapas. A consulta prévia (Licença Prévia - LP) tem por objetivo obter do órgão ambiental uma primeira avaliação sobre a possibilidade de se implantar o empreendimento em uma determinada região pretendida e também esclarecer se haverá a necessidade de elaborar o Estudo de Impacto Ambiental (EIA-Rima). O pedido da licença de instalação (LI) deve ser acompanhado de um documento de caracterização do empreendimento, descrevendo os processos e os equipamentos que serão instalados e as atividades a serem desenvolvidas. A licença de operação (LO) é concedida após a devida instalação da atividade, quando o órgão ambiental analisa sua conformidade com os planos e as informações apresentadas por ocasião da concessão da licença de instalação (VALLE, 2002).

Assim, o licenciamento ambiental é constituído de diretrizes normativas e instrumentos que regulam a instalação e o funcionamento de atividades, efetiva ou potencialmente poluidoras, ou seja, que possam gerar impactos ambientais. O conceito de impacto possui diversas definições, envolvendo diversas abordagens. Para efeito deste artigo, foi usado o conceito amplo de impacto, compreendido como qualquer alteração, decorrente de atividades, nos aspectos bióticos e abióticos, sociais e culturais do meio ambiente (VALLE, 2002).

O CONAMA (1986) considera impacto ambiental qualquer alteração das propriedades físicas, químicas e biológicas do meio ambiente, causada por qualquer forma de matéria ou energia resultante das atividades humanas que, direta ou indiretamente, afetam: a saúde, a segurança e o bem-estar da população, as atividades sociais e econômicas, a biota, as condições estéticas e sanitárias do meio ambiente e a qualidade dos recursos naturais. 
Os impactos ambientais são mensurados e controlados através de um processo de Avaliação de Impacto Ambiental (AIA), que se caracteriza como um instrumento de gestão da atividade potencialmente poluidora, estabelecendo procedimentos de análise desses impactos ambientais (CHAVES; RODRIGUES, 2006).

O Estudo de Impacto Ambiental (EIA) e o Relatório de Impacto Ambiental (Rima) foram estabelecidos por meio da Resolução CONAMA 001/86, que define que todas as atividades potencialmente poluidoras devem ser licenciadas. O EIA-Rima é um documento técnico que descreve as características do empreendimento, enfatizando os processos, procedimentos e impactos das atividades a serem licenciadas. Devido à linguagem técnica do EIA, foi necessário criar um documento mais resumido e com uma linguagem mais simples, permitindo que toda a sociedade pudesse ter acesso às informações do empreendimento. Desta maneira, foi criado o Relatório de Impacto Ambiental (Rima).

Embora exista uma lista de empreendimentos que requerem a elaboração do EIA/Rima, em alguns casos o órgão ambiental pode solicitar somente um Relatório Ambiental Preliminar RAP. Esse é um documento primário que visa à concessão da LP (Licença Prévia) a qualquer empreendimento. De acordo com o RAP, exige-se ou dispensa-se o EIA/Rima para a obtenção da LP. É importante destacar que o RAP é um estudo que avalia os possíveis impactos, preliminarmente, e que se estes forem considerados efetivos e potencialmente degradantes deverá ser elaborado o EIA/Rima, ao qual se dará publicidade, garantindo a realização de audiências públicas, quando couber, de acordo com a regulamentação (CONAMA 237/97, art. $3^{\circ}$ ).

A realização desses estudos deverá ser feita por equipes técnicas multidisciplinares, que deverão contemplar as seguintes etapas: diagnóstico ambiental, que caracteriza a situação ambiental da área antes da implantação do empreendimento, considerando o meio físico, biológico e social; análise dos impactos ambientais do empreendimento e de suas alternativas; definição das medidas mitigadoras e elaboração dos programas de monitoramento dos impactos negativos (FILHO; SOUZA, 2004).

Como aponta Bermann (2007), a implantação de empreendimentos para a produção de energia hidrelétrica é invariavelmente acompanhada de impactos que representam alterações nas condições do ambiente em que se inserem. Embora existam impactos que se mostrem recorrentes, independentemente das características construtivas e operacionais dos empreendimentos, suas manifestações e aspectos qualitativos apresentam notáveis 
variações que se relacionam diretamente com o nível de integridade ambiental da área de influência do empreendimento (BERMANN, 2007).

Em relação aos aspectos sociais, é necessário desenvolver mais estudos sobre as aspirações, prioridades e atitudes das populações envolvidas na implantação de um empreendimento, pois se pressupõe que a população tenha sido amplamente informada sobre o empreendimento objeto de licenciamento. Para garantir a participação popular no processo devem ser realizadas as audiências públicas, regulamentadas pela resolução CONAMA $009 / 87$.

A participação popular no processo de licenciamento ambiental é fundamental. Geralmente, os impactos ambientais importantes, relacionados diretamente ao cotidiano da população, não são apresentados a ela e discutidos adequadamente. Estes impactos podem interfererir na economia local (aumento no valor dos aluguéis, aumento temporário na oferta de emprego, ampliação do comércio e aumento da população), interferir na área social (brigas, assédio a menores, tráfico de drogas, maior demanda de serviços públicos, como: educação, saúde e segurança) e também na infraestrutura local (maior trânsito de veículos e desgastes da malha viária).

Porém, a construção de uma PCH não apresenta somente efeitos negativos do ponto de vista socioambiental, há também pontos positivos a serem considerados, como: geração de emprego e renda, qualificação de mão de obra, expansão da infraestrutura local e regional, dinamização da economia local e regional e aumento da arrecadação tributária municipal (SANCHEZ, 2008).

\section{METODOLOGIA}

Neste estudo, foi adotada como metodologia de pesquisa a análise do RAP da PCH, sendo observados os aspectos socioambientais mensurados pelo empreendedor. Após essa avaliação, foi elaborado um questionário, com questões abertas e fechadas, relacionadas aos aspectos socioambientais, e aplicado à população local, priorizando as comunidades do entorno da $\mathrm{PCH}$.

Ao todo foram entrevistadas 130 pessoas das comunidades e mais 15 pessoas de setores públicos do município de Queluz-SP. As entrevistas foram realizadas por meio do método 
survey, ou seja, levantamento das opiniões dos participantes. A pesquisa foi de natureza qualitativa, não sendo necessária a aplicação de procedimentos estatísticos quantitativos.

A pesquisa qualitativa é utilizada para estudos voltados à percepção, à intuição e à subjetividade, sendo direcionada para a investigação dos significados das relações humanas, nas quais as ações são influenciadas pelas emoções e/ou sentimentos diante das situações vivenciadas no cotidiano. Neste método de pesquisa não são necessárias grandes amostragens (GIL, 1991; MYNAYO, 1994; SEVERINO, 2002).

As informações obtidas durante as entrevistas foram organizadas em categorias previamente definidas, em função das respostas obtidas. As categorias foram agrupadas por tema e opinião, sendo analisadas por meio da aplicação de procedimentos de estatística descritiva.

O questionário foi organizado com perguntas de ordem pessoal, como: idade, grau de escolaridade, local de moradia e renda familiar, e questões relativas aos aspectos socioambientais relacionados com a $\mathrm{PCH}$, como: conhecimento da $\mathrm{PCH}$, participação do processo de licenciamento, conhecimento sobre aspectos positivos e negativos da construção da PCH e opiniões quanto ao empreendimento como um todo.

\section{Caracterização e identificação da Pequena Central Hidrelétrica Queluz}

A PCH-Queluz está localizada a $22^{\circ} 32^{\prime}$ de latitude sul e $44^{\circ} 48^{\prime}$ de longitude oeste, no município de Queluz, estado de São Paulo, na bacia do rio Paraíba do Sul (Figura 1). Queluz (Figura 2) apresenta uma área total de $350 \mathrm{~km}^{2}$ e população aproximada de 11.325 habitantes (IBGE, 2010).

O empreendimento $\mathrm{PCH}$-Queluz pertence à Usina Paulista de Energia, Grupo Alupar, o qual concedeu a construção da PCH à empresa Empreendimentos Patrimoniais Santa Gisele Ltda, de São Paulo.

A maior parte da energia produzida já foi adquirida pela empresa Sadia, sendo distribuída pela região do Vale Histórico do Paraíba, em municípios como: Cruzeiro, Lavrinhas, Silveiras, Queluz, Areias, São José do Barreiro, Arapeí e Bananal (BORGES; MEIRA, 2009).

A PCH-Queluz apresenta área alagada de $0,55 \mathrm{Km}^{2}$, área do reservatório de $1,27 \mathrm{Km}^{2} \mathrm{e}$ capacidade instalada de 30 MW (HABTEC, 2012).

O RAP foi aprovado com o argumento principal de que a instalação da PCH-Queluz (Figura 3) não teria interferência significativa nos processos dinâmicos da bacia do rio Paraíba do Sul, 


\section{área de influência do empreendimento, e os impactos ambientais mensurados foram} caracterizados como de baixa magnitude.

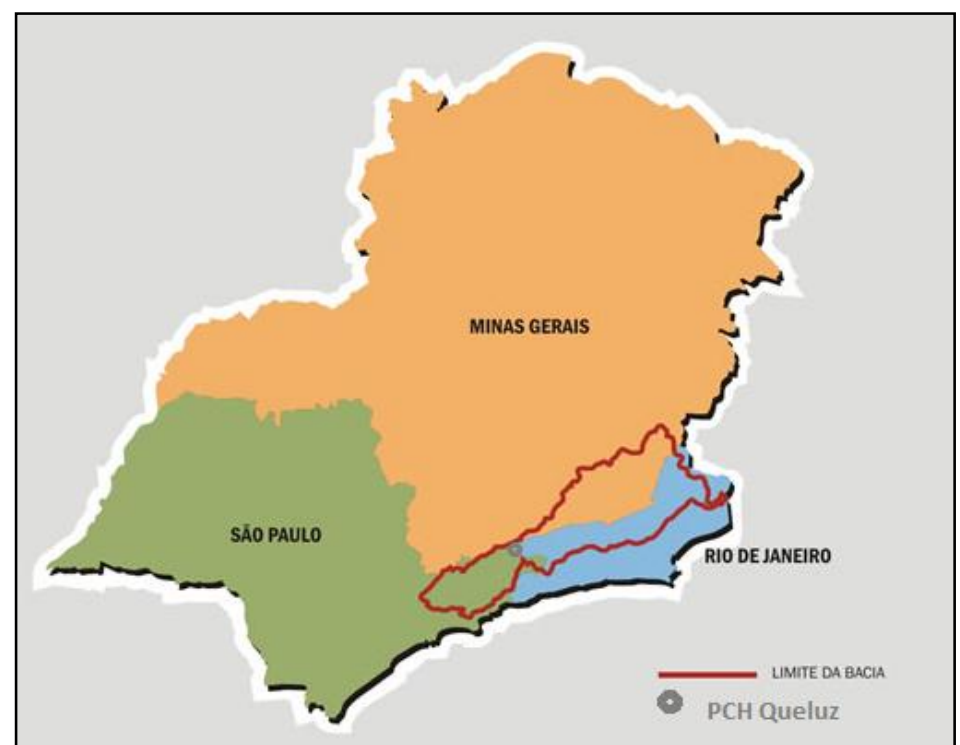

Figura 1 - Bacia Hidrográfica do Rio Paraíba do Sul, localização da PCH Queluz - São Paulo e sua interface com os estados do RJ e MG.

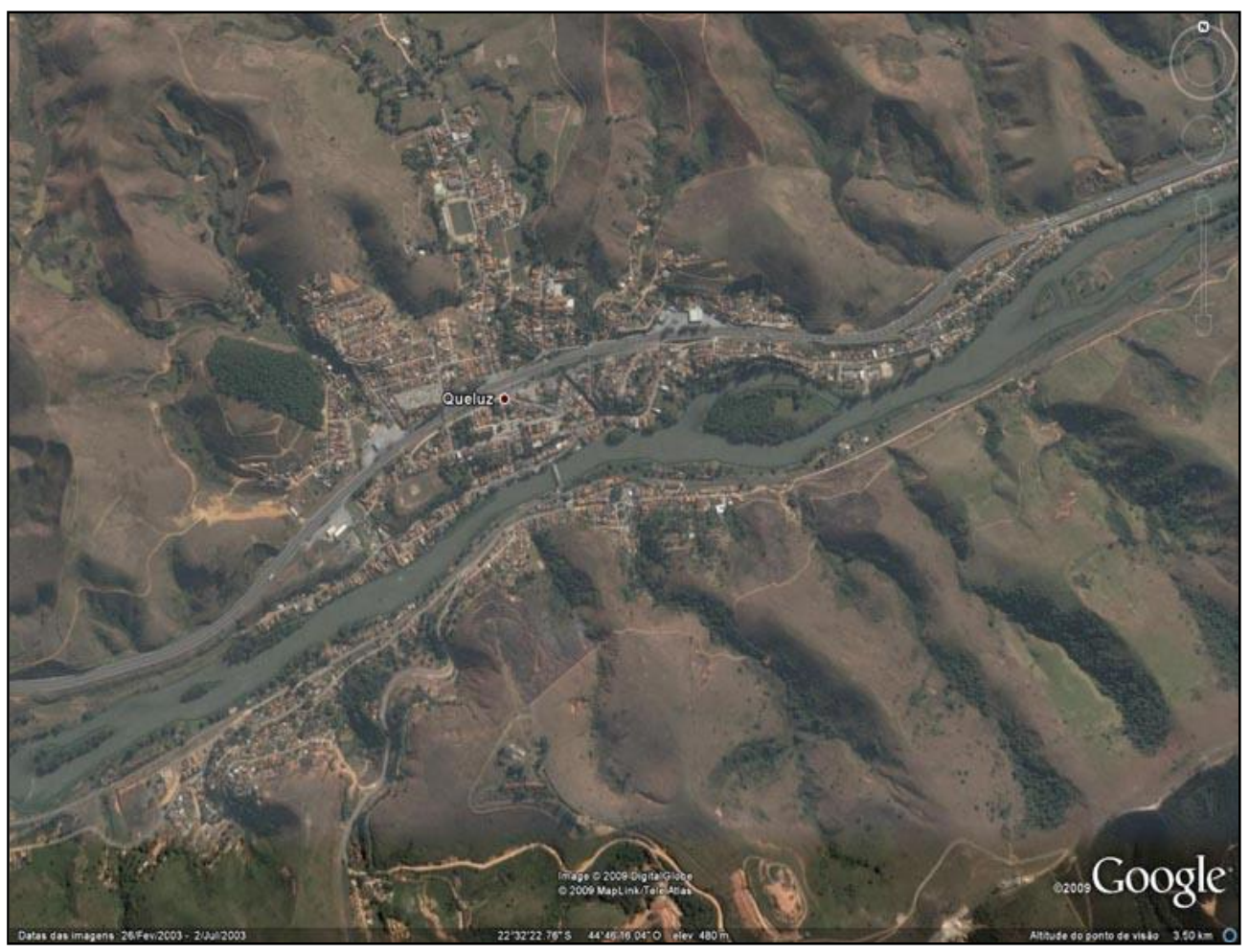

Figura 2 - Localização do município de Queluz-SP. 


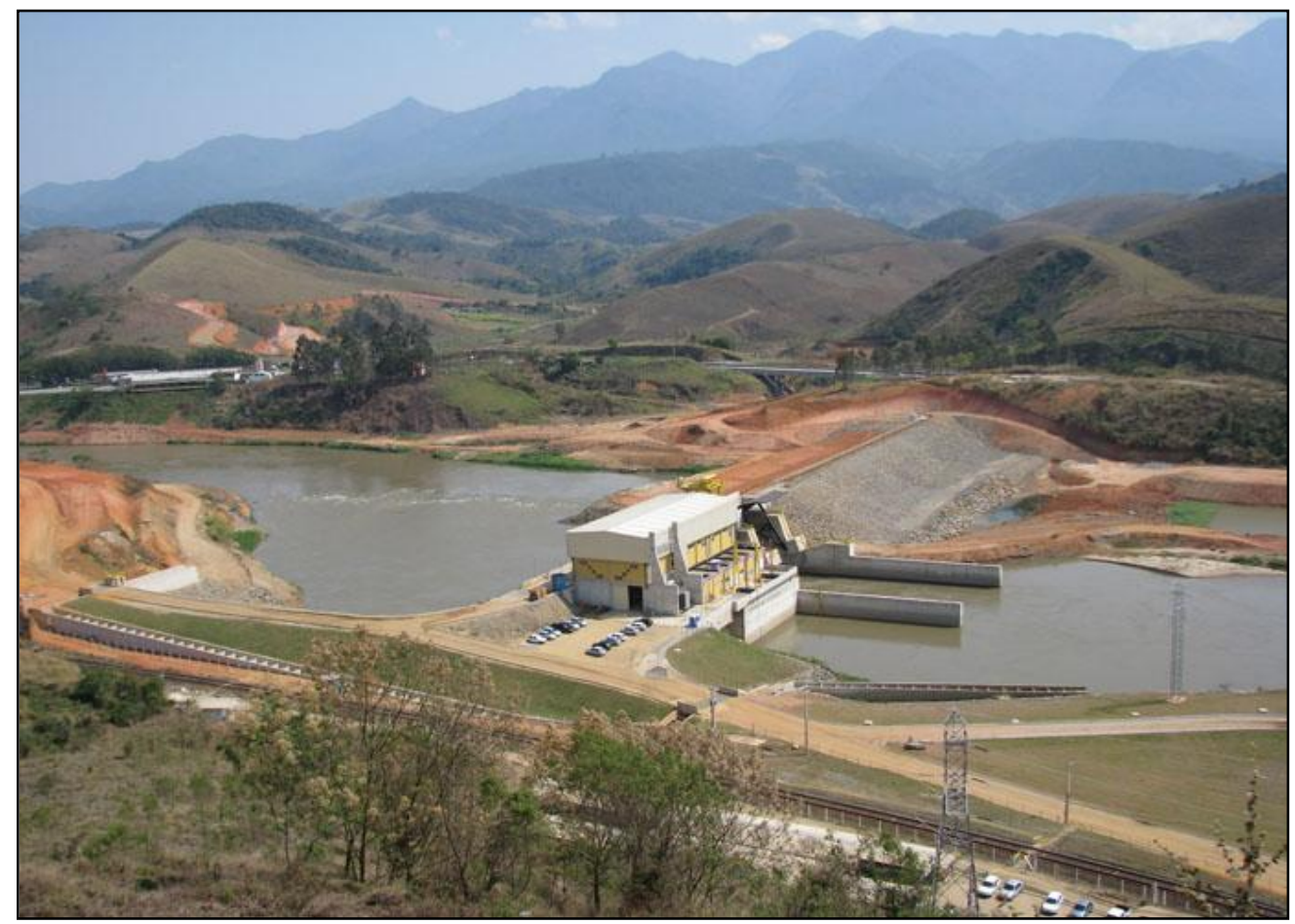

Figura 3 - A PCH-Queluz em operação (HABTEC, 2012).

\section{RESULTADOS E DISCUSSÃO}

\section{Análise dos aspectos e impactos socioambientais mensurados no RAP da PCH-Queluz}

Analisando o RAP da PCH-Queluz, foi possível observar diagnósticos do meio físico, biótico e antrópico. Em relação à vegetação na área de influência da $\mathrm{PCH}$, não foi caracterizada a presença de mata ciliar, somente indivíduos arbóreos isolados e vegetação predominantemente rasteira, formada por gramíneas e sapé. Em termos de biodiversidade, a vegetação não apresenta alta relevância, sendo o valor ecológico atribuído ao controle de processos erosivos e refúgio de fauna.

Na caracterização da fauna, destaca-se a presença das seguintes espécies: mão-pelada, gambá, cachorro do mato e preá. Foram registradas 157 espécies de aves, com destaque para 12 espécies endêmicas. A bacia do rio Paraíba do Sul se destaca pela alta biodiversidade de ictiofauna, ocorrendo a espécie surubim, endêmica na região e ameaçada de extinção, e a espécie guaru, que se encontra vulnerável na lista de espécies ameaçadas no estado de São Paulo (HABTEC, 2012).

Os principais impactos descritos no RAP foram:

$\checkmark$ interferências em áreas de autorizações e concessões minerais do reservatório; 
$\checkmark$ início ou aceleração de processos erosivos;

$\checkmark$ alterações na fauna aquática a montante da barragem;

$\checkmark$ comprometimento de rotas migratórias;

$\checkmark$ criação de expectativas;

$\checkmark$ alteração das arrecadações municipais;

$\checkmark$ alterações no mercado de trabalho;

$\checkmark$ intensificação do tráfego;

$\checkmark$ aumento da oferta de energia elétrica para a região;

$\checkmark$ interferências com lazer e infraestrutura viária.

Analisando esses impactos, é possível considerar que a interferência às concessões minerais é pouco significativa. O recurso mineral explorado na região é o granito e a obra somente inviabilizará essa exploração em uma pequena área ocupada pelo reservatório (BORGES; MEIRA, 2009).

O período de construção da $\mathrm{PCH}$ coincide com o de maior ocorrência de processos erosivos, porém este impacto é considerado de abrangência local e duração temporária. Se tomadas as devidas medidas preventivas e de controle, esse impacto não provocará alterações significativas à qualidade ambiental na região.

A formação do reservatório no rio Paraíba do Sul e a consequente mudança na velocidade de circulação da água podem afetar algumas espécies da fauna aquática. A criação de barreiras à migração das espécies de peixes mostra-se mais crítica para a espécie curimbatá (HABTEC, 2012).

Em relação à geração de expectativas, é normal que isto aconteça sempre que são anunciadas mudanças locais que, eventualmente, alterem o cotidiano das comunidades. Estas expectativas podem ser positivas ou negativas, de acordo com o segmento da sociedade afetada, direta ou indiretamente (BORGES; MEIRA, 2009).

Com a construção da PCH, é evidente a ocorrência de alterações no mercado de trabalho e economia na região, com a criação de novos postos de trabalho e maior desenvolvimento de atividades comerciais.

Durante a execução da obra ocorrerá a intensificação do tráfego rodoviário, sendo os efeitos sentidos nas vias municipais e estradas rurais localizadas nas áreas de entorno do empreendimento. 
As mudanças no rio Paraíba do Sul, com a formação do reservatório, representam alteração na paisagem local, pois o rio é usado para recreação, lazer e pesca.

O principal impacto positivo da PCH é a melhoria da qualidade de energia nos municípios de Queluz, Lavrinhas e Cruzeiro, aspecto que pode estimular o estabelecimento de novas indústrias na região.

O RAP do empreendimento apresenta um plano com as medidas mitigatórias e programas ambientais referentes aos impactos identificados (Tabela 1).

Quadro 1 - Principais impactos mensurados e os programas com as medidas mitigadoras previstas no RAP da PCH-Queluz.

\begin{tabular}{|c|c|c|}
\hline PROGRAMAS & IMPACTOS MENSURADOS & NATUREZA \\
\hline $\begin{array}{l}\text { Programa de Acompanhamento } \\
\text { de Atividades de Mineração }\end{array}$ & $\begin{array}{l}\text { Interferências em áreas de autorizações e concessões de } \\
\text { mineração com a construção do reservatório }\end{array}$ & Mitigação \\
\hline $\begin{array}{l}\text { Programa de Limpeza da Bacia } \\
\text { de Acumulação }\end{array}$ & Alterações na fauna aquática a montante da barragem & Prevenção \\
\hline $\begin{array}{c}\text { Programa de Monitoramento } \\
\text { Limnológico e de Qualidade da } \\
\text { Água }\end{array}$ & Alterações na fauna aquática a montante da barragem & $\begin{array}{l}\text { Prevenção e } \\
\text { Controle }\end{array}$ \\
\hline $\begin{array}{l}\text { Programa de Comunicação } \\
\text { Social }\end{array}$ & $\begin{array}{c}\text { Alterações no mercado de trabalho } \\
\text { Alteração na renda regional e nas arrecadações } \\
\text { municipais } \\
\text { Intensificação do tráfego } \\
\text { Aumento na oferta de energia local }\end{array}$ & Mitigação \\
\hline $\begin{array}{l}\text { Programa de Proteção das } \\
\text { Margens e Recuperação das } \\
\text { Áreas Degradadas }\end{array}$ & Início ou Aceleração de Processos Erosivos & $\begin{array}{l}\text { Compensação e } \\
\text { Mitigação }\end{array}$ \\
\hline $\begin{array}{l}\text { Programa de Consolidação da } \\
\text { Unidade de Conservação }\end{array}$ & $\begin{array}{l}\text { Desmatamentos e interferências sobre a flora e fauna } \\
\text { locais }\end{array}$ & Compensação \\
\hline $\begin{array}{l}\text { Programa de Monitoramento } \\
\text { da Ictiofauna }\end{array}$ & $\begin{array}{l}\text { Alterações na fauna aquática a montante da barragem } \\
\text { Comprometimento de rotas migratórias }\end{array}$ & $\begin{array}{l}\text { Prevenção e } \\
\text { Controle }\end{array}$ \\
\hline
\end{tabular}

Fonte: RAP - Relatório Ambiental Preliminar (2008), empresa Habtec.

O RAP enfatizou alguns impactos importantes, porém é necessário observar que a concomitância desses impactos pode ser muito mais complexa do que a aparência revela, ou seja, aparentemente são poucos os impactos mensurados, mas muito provavelmente surgem outros impactos indiretos importantes ao município. Citamos como exemplo o aumento da violência, ocasionado pelo aumento populacional em um município sem infraestrutura adequada para acolher a mão de obra necessária durante a obra da PCH, impacto este que não foi mencionado no RAP pelo empreendedor.

Como medidas mitigatórias, o RAP menciona algumas ações específicas, conforme a Tabela 1. Porém, os programas ambientais sugeridos pelo empreendedor são de caráter técnico, o 
que é positivo, mas não contemplam ações sociais e culturais, como programas de educação ambiental e projetos específicos para reduzir os impactos secundários ou terciários.

\section{Análise dos aspectos e impactos socioambientais caracterizados nas entrevistas.}

A partir da análise dos dados, foi possível notar que a participação municipal no processo de licenciamento é bastante limitada, pois o município de Queluz não possui um setor para cuidar do meio ambiente e nem legislações municipais relacionadas ao uso e ocupação do solo. Assim, o empreendedor atendeu as legislações ambientais vigentes no âmbito federal e estadual, o que não atende plenamente as especificidades da região.

Quanto à divulgação do empreendimento, sabe-se que, para seu licenciamento ambiental, é obrigatório que o mesmo seja discutido publicamente e de forma participativa. $\mathrm{Na}$ implantação da $\mathrm{PCH}$, porém, há dúvidas quanto à elaboração, de fato, das audiências, bem como sobre a participação popular efetiva no processo.

Dos entrevistados, $70 \%$ disseram que conheciam o projeto da $\mathrm{PCH}-\mathrm{Queluz}$, mas a maioria desses não soube identificar os impactos da obra, o que mostra certa falha no processo de comunicação do empreendedor com as partes interessadas.

Em relação ao conhecimento do RAP, foi constatado que a grande maioria dos entrevistados (81\%) desconhecia este documento, fato que pode sinalizar uma falha no processo de informação e, consequentemente, de participação. Pois, o desconhecimento do RAP, documento que trata justamente dos impactos do empreendimento, diminui a qualidade da participação, uma vez que os cidadãos possuem informações limitadas sobre os efeitos da construção da PCH.

A maioria dos entrevistados (92\%) disse não ter participado de nenhuma reunião ou audiência pública sobre o empreendimento, mais um indício de que a participação popular foi pouco efetiva no processo de licenciamento ambiental da PCH-Queluz.

Sobre os programas socioambientais relacionados ao empreendimento, somente $30 \%$ dos entrevistados disseram ter conhecimento, sendo que a maioria desses ficou sabendo por veículos de comunicação informais, como conversas com os próprios moradores da região. Aparentemente, o programa de comunicação mencionado pelo empreendedor como medida mitigatória foi pouco abrangente.

Os entrevistados (81\%) citaram a geração de empregos como o impacto positivo mais importante do empreendimento, porém, disseram também que as vagas de emprego estavam sendo ocupadas por mão de obra externa. Este resultado revela que o discurso 
utilizado por grande parte dos empreendimentos, em relação à geração de empregos nas obras, deve ser analisado com cautela, pois pode não retratar fielmente a realidade. A maioria dos entrevistados apresenta uma percepção imediatista quanto à geração de emprego e se esquece de que a maior parte dessas vagas é temporária e a maior demanda ocorre na fase da obra.

O impacto negativo mais citado pelos entrevistados $(68,5 \%)$ foi a má conservação das ruas, que está diretamente relacionada com o aumento do fluxo de veículos, principalmente caminhões utilizados nas obras.

Os questionários apontam também que os entrevistados percebem os impactos mais imediatos da obra e acabam deixando de discutir impactos de médio e longo prazo, que podem surgir em função da operação do empreendimento.

Em relação ao destino da energia elétrica produzida pela $\mathrm{PCH}, 48 \%$ dos entrevistados disseram que essa seria comercializada com empresas da região. Entretanto, $52 \%$ dos entrevistados relataram que não sabiam o destino da energia gerada. Novamente evidenciando problemas no processo de comunicação.

A maioria da população entrevistada (70\%) analisou a $\mathrm{PCH}-\mathrm{Queluz}$ como ponto positivo, referindo-se claramente à geração de empregos e à instalação de novas empresas na região. Os representantes do setor público municipal disseram que a $\mathrm{PCH}$ gera empregos, destacando o aumento de arrecadação de impostos e maior desenvolvimento da economia local e regional. Os entrevistados relataram que a demanda pelos serviços públicos municipais já vem aumentando. Este impacto quase sempre não é avaliado de maneira adequada pelos estudos ambientais e acaba gerando passivos sociais aos governos municipais.

Os programas socioambientais apresentados pelo empreendedor não contemplam de maneira satisfatória os impactos mencionados, uma vez que os diversos programas previstos (Acompanhamento de atividades de mineração, Limpeza de Bacia de acumulação, Monitoramento Limnológico e de qualidade da água, Comunicação Social, proteção das margens e recuperação de áreas degradadas, Consolidação da unidade de conservação e Monitoramento da Ictiofauna) não foram citados pelos entrevistados. Cabe observar que a maioria desses programas possui um caráter técnico e voltado para uma atuação da mitigação dos impactos. Entretanto, a falta de maior conhecimento das diversas atividades 
aponta para problemas em relação ao programa de Comunicação Social, evidenciando falhas no diálogo entre o empreendedor e a população local.

As informações do empreendimento e do processo de licenciamento da $\mathrm{PCH}$ não estavam disponíveis nos órgãos municipais; fato que acabou dificultando muito a obtenção dos dados.

As medidas mitigatórias propostas também não satisfazem adequadamente os impactos elencados. Estas medidas somente serão formuladas de maneira coerente quando houver uma maior integração entre empreendedores, gestão municipal e população atingida, sendo fundamental a existência de programas que atendam aos anseios das partes interessadas (BACCI, et al. 2006, CAMILLO, et al. 2007).

Nesse sentido, o desenvolvimento de um programa de educação ambiental voltado para toda a população da região, não devendo ser somente focada em escolas locais (educação formal), mas atingindo a maior parte da população, seria necessário, pois facilitaria a comunicação entre o empreendimento e as partes interessadas, criando condições para uma participação mais ativa, a formação de uma cultura socioambiental e formas de governança que articulem o empreendedor, a comunidade local e representantes do poder político local. Nenhum entrevistado disse ter lido o RAP, participado de reuniões formais ou audiências públicas, e esta falta de informação talvez explique o desinteresse popular pelo debate, uma vez que os moradores não tem conhecimento dos impactos da PCH. Desse modo, aliando-se a falta de informação, o tecnicismo que orienta a conduta dos procedimentos de licenciamento ambiental e a exclusão da população nas decisões, os procedimentos acabam sendo realizados de forma autoritária, levando em consideração, exclusivamente, as opiniões dos técnicos, perpetuando uma lógica tecnicista, na qual a percepção das pessoas atingidas são desconsideradas. Isto em nada contribui para a formação de uma ação cidadã, muito menos para a percepção da importância ou não da construção de um empreendimento e a consolidação de uma sociedade democrática, na qual os riscos devem ser discutidos de forma ampla.

\section{CONSIDERAÇÕES FINAIS}

Todo empreendimento relacionado à produção de energia elétrica é impactante do ponto de vista social e ambiental e, desse modo, o que importa em uma análise é considerar a 
intensidade e a duração desses impactos e, principalmente, a eficiência das medidas compensatórias e de controle apresentadas pelos empreendedores da obra.

A não "obrigação" da elaboração do EIA-Rima para as PCHs é um sinal de alerta, que deve ser debatida com maior amplitude pelos agentes envolvidos (poder público, comunidades locais, empreendedores e ambientalistas). Uma vez que tais empreendimentos podem aproveitar essa oportunidade e propor várias PCHs em uma mesma bacia hidrográfica, fato que pode proporcionar problemas ambientais significativos para uma região. A PCH-Queluz, localizada na bacia do Rio Paraíba do Sul, serve como exemplo desta situação, pois na mesma região foi instalada a PCH-Lavrinhas, ampliando os riscos socioambientais para esta bacia. O problema se agrava ainda mais pelo fato desta região ser fortemente industrializada e densamente ocupada pela população. Neste caso específico, também ocorre uma complexidade administrativa, já que a referida bacia hidrográfica se insere em mais de um estado, o que reforça, naturalmente, os conflitos relacionados ao uso dos recursos hídricos. $\mathrm{Na}$ análise do RAP da PCH-Queluz, e dos questionários, é possível dizer que faltam informações, os impactos são tratados de forma reducionista e não são analisados considerando a complexidade socioambiental. A participação pública e popular no processo de licenciamento é restrita e pouco eficaz, não ocorrendo presença efetiva da comunidade na tomada das decisões.

A implantação de uma PCH, assim como qualquer intervenção no meio ambiente, ocasiona impactos que podem ser positivos ou negativos. Nesse caso, devem sempre ser analisados sob a ótica socioambiental, assim como também em relação a sua contribuição para o desenvolvimento local e regional.

As $\mathrm{PCH}$ apresentam algumas vantagens, pois, normalmente, encontram-se localizadas próximas aos centros consumidores, o que representa economia na transmissão, facilidade para isenções de tarifas e maior garantia de venda da energia elétrica.

A população entrevistada demonstrou percepção favorável à instalação da $\mathrm{PCH}$, porém é nítida sua falta de informação e conhecimento sobre o empreendimento, evidenciado pela falta de um amplo debate sobre os impactos do empreendimento, aspecto este que exige maior atenção por parte dos empreendedores, governos e populações afetadas. É interessante observar que, apesar da maioria dos entrevistados ser a favor da construção da $\mathrm{PCH}$, poucos sabem o que isso pode significar para sua vida e para a comunidade. Programas 
de comunicação e educação ambiental seriam opções importantes para amenizar este problema.

Adotando um viés dialético, a PCH-Queluz representa para o poder público maiores recursos financeiros e ao mesmo tempo mais despesas e gastos para atender o aumenta da demanda por serviços públicos; para o cidadão, mais emprego e conflitos sociais ocasionados por mudanças nos hábitos locais; para outros representa impactos socioambientais (positivos e negativos), e assim sucessivamente. O ponto de vista se modifica de acordo com os interesses e ideologias de cada um e, por isso, muitas vezes não se consegue encontrar uma definição para o bem comum. Dessa forma, o desenvolvimento de práticas participativas e deliberativas são formas mais democráticas de gerenciamento dos conflitos socioambientais que favorecem o emponderamento da população local, a fim de garantir que as decisões públicas, no caso a construção de uma $\mathrm{PCH}$, estejam de acordo com os interesses dos membros da comunidade, evitando que a posse de capital econômico ou político prevaleça na definição das ações públicas (cf. HABERMAS, 1997).

Uma das características importantes do processo de licenciamento é a participação da população, principalmente quando se trata de projetos com impactos significativos. Outra participação fundamental no processo é a atuação pública, que deve informar e decidir considerando os seus pontos de vista e opiniões da sociedade. Portanto, a participação pública no processo, atuando como agente negociador é uma tarefa essencial. As comunidades devem acompanhar o processo de licenciamento desde o início, participando das decisões e monitorando a execução por parte do empreendedor das medidas mitigatórias e compensatórias, assim como ajudar a fomentar a construção de uma cultura cívica e a almejada consciência ambiental. A predominância de uma concepção reducionista e hegemônica determina que os modos de vida e as formas de uso dos recursos naturais sigam a lógica do mercado (Zhouri et al., 2005), impedindo que as comunidades sejam reconhecidas nos processos de licenciamento ambiental.

Interesses de particulares ou de grupos políticos não devem se sobressair em relação aos interesses das comunidades. Da maneira que é conduzido o processo de licenciamento ambiental para o funcionamento de uma $\mathrm{PCH}$, fica a percepção de que as decisões muitas vezes são tomadas por motivações políticas e econômicas, em vez de serem baseadas em critérios socioambientais com a participação de técnicos e da população. Esta representação poderia ser menos proeminente se tivéssemos maior participação popular nos processos e 
nas decisões. Contudo, os atuais fóruns de participação, que constam no processo de licenciamento encontram problemas para sua efetivação.

As audiências públicas tendem a favorecer o confronto e não a negociação, e o formato de execução é inadequado, pois impede que sejam prestados esclarecimentos efetivos para a população. A participação popular no licenciamento ocorre muito tarde, quando muitas decisões importantes sobre o projeto já foram tomadas. A maior parte da população dispõe de pouca informação do projeto e não tem condições de compreender a informação de caráter técnico e científico dos projetos. Como aponta Sanchez (2008), existe um déficit comunicativo implícito, uma vez que os "técnicos" se colocam acima dos cidadãos, fazendo com que o debate público seja direcionado por um linguajar técnico que ajuda na exclusão da população.

Nesse sentido, faz-se necessário o desenho de novos modelos de participação dentro dos processos de licenciamento ambiental, que garanta uma efetiva atuação da população local no debate sobre os impactos da construção de um empreendimento hidrelétrico.

\section{REFERÊNCIAS}

ANDRADE, J. S. O. Pequenas Centrais Hidrelétricas: análise das causas que impedem a rápida implantação de PCHs no Brasil. Dissertação (Mestrado em Regulação da Indústria de Energia) - Universidade Salvador, UNIFACS, Salvador, 2006.

ANEEL. Agência Nacional de Energia Elétrica. Banco de Informações de Geração. Disponível em: <www.aneel.gov.br>. Acesso em: 21 nov. 2012.

BACCI, D. C.; LANDIM, P. M. B.; ESTON, S. M. Aspectos e impactos ambientais de pedreira em área urbana. REM: R. Esc. Minas, v. 59, n. 1, p. 47-54, 2006.

BARBOSA, T.A.S.; DUPAS, F.A. Matriz simplificada para avaliar impactos ambientais em Pequenas Centrais Hidrelétricas (PCH). Revista Brasileira de Energia, v. 12, n. 2, p. 1-9, 2008.

BERMANN, C. Impasses e controvérsias da hidreletricidade. Estudos Avançados, v. 21, n. 59, p. 139-153, 2007. 
BORGES, R.R.; MEIRA, R.L. Impactos socioambientais de Pequenas Centrais Hidrelétricas e Estudo de Caso PCH-Queluz-SP e Lavrinhas-SP no Rio Paraíba do Sul. Cadernos UniFOA, edição especial, p. 23-35, 2009.

CAMILlO, C. S.; ANJOS-AQUINO, E. A. C.; AlBUQUERQUE, L. B. Análise crítica do Estudo Ambiental Preliminar do projeto urbanístico "Reviva Lagoa Itatiaia", em Campo Grande/MS. Interações. Revista Internacional de Desenvolvimento Local, v. 8, n. 1, p. 45-53, 2007.

CARVALHO E ALBUQUERQUE, H. M. Inserção das Pequenas Centrais Hidrelétricas Promovida pelo Programa de Incentivo às Fontes Alternativas de Energia Elétrica - PROINFA. Dissertação (Mestrado em Regulação da Indústria de Energia) - Universidade Salvador, UNIFACS, Salvador, 2006.

CENDRETTI, E. C.; SANTOS, E. M.; BIONDI, A. E. C. Análise dos impactos sócio-ambientais da construção de uma PCH: estudo de caso da Usina Paulista Queluz Energia S.A. Monografia de Pós-Graduação em Educação Ambiental. Faculdades Integradas de Cruzeiro, Cruzeiro-SP, 2009.

CHAVES, M. P. S. R.; RODRIGUES, D. C. B. Desenvolvimento Sustentável: limites e perspectivas no debate contemporâneo. Interações. Revista Internacional de Desenvolvimento Local, v. 8, n. 13, p. 99-106, 2006.

CONAMA. Conselho Nacional de Meio Ambiente. Resolução n. 001, de 23 de janeiro de 1986. Dispõe sobre critérios básicos e diretrizes gerais para o Relatório de Impacto Ambiental (RIMA). Disponível em: <http://www.mma.gov.br>. Acesso em: 09 jun. 2009.

ERENO, D. Pequenas em expansão. Pesquisa FAPESP, v. 157, p. 80-83, 2009.

FILHO, G.L.T.; GALHARDO, C.R.; DUARTE, E.R.B.C.; NASCIMENTO, J.G.A. Impactos sócioeconômicos das pequenas centrais hidrelétricas inseridas no programa de incentivo as fontes alternativas de energia (PROINFA). Revista Brasileira de Energia, v. 14, n. 1, p. 145166, 2008.

FILHO, J. F. P.; SOUZA, M. P. O licenciamento ambiental da mineração no quadrilátero ferrífero de Minas Gerais - uma análise da implementação de medidas de controle ambiental 
formuladas em EIAs/RIMAs. Revista Engenharia Sanitária Ambiental, v. 9, n. 4, p. 343-349, 2004.

FREY, K. Políticas públicas: um debate conceitual e reflexões referentes à prática da análise de políticas públicas no Brasil. Revista Planejamento e Políticas Públicas, n. 21, jun 200.

GIL, A. C. Como elaborar projetos de pesquisa. São Paulo: Atlas, 1991.

GOLDEMBERG, J.; LUCON, O. Energia e Meio Ambiente no Brasil. Estudos Avançados, v. 21, n. 59, p.7-20, 2007.

HABERMAS, J. Direito e Democracia: entre facticidade e validade. Rio de Janeiro: Tempo Brasileiro, 1997.

HABTEC. Habtec Engenharia Ambiental. Usina Paulista Queluz. Disponível em: <http://www.habtec.com.br/experiencia/clientes/usina-paulista-queluz-de-energia/>. Acesso em: 25 abr. 2012.

IBGE. Instituto Brasileiro de Geografia e Estatística. Cidades. Disponível em: <http://www.ibge.gov.br>. Acesso em: 15 jun. 2010.

LEÃO, L. L. Considerações sobre impactos socioambientais de Pequenas Centrais Hidrelétricas (PCHs) - modelagem e análise. Dissertação (Mestrado em Desenvolvimento Sustentável) - Universidade de Brasília, UNB, Brasília, 2008.

LEFF, E. Epistemologia Ambiental. São Paulo: Cortez, 2007.

LITTLE, P. Os conflitos socioambientais: um campo de estudo e ação política. In: Bursztin, M. (org.) A difícil sustentabilidade - política energética e conflitos ambientais. Rio de Janeiro: Editora Garamond, 2001.

MINAYO, M. C. S. Pesquisa social: teoria, método e criatividade. Rio de Janeiro: Vozes, 1994. RAP - RELATÓRIO AMBIENTAL PRELIMINAR. Pequena Central Hidrelétrica - Queluz. HABTEC Engenharia Sanitária e Ambiental, Rio de Janeiro, 2008. 
ROLIM, M. Notas sobre um inventário para o patrimônio arquitetônico do setor de energia elétrica em São Paulo. História da Energia Elétrica no Estado de São Paulo (1890-2005). São Paulo: Fundação Patrimônio Histórico da Energia de São Paulo, 2009.

SANCHEZ, L. H. Avaliação de Impacto Ambiental: conceitos e métodos. São Paulo: Oficina de textos, 2008.

SEVERINO, A. J. Metodologia do Trabalho Científico. São Paulo: Cortez, 2002.

SILVA NETO, B. Desenvolvimento sustentável: uma abordagem baseada em sistemas dissipativos. Ambiente e Sociedade, v. 11, n. 1, p. 15-31, 2008.

VAINER, C.B. Recursos hidráulicos: questões sociais e ambientais. Estudos Avançados, v. 21, n. 59, p. 119-137, 2007.

VALLE, C. E. Qualidade Ambiental: ISO 14.000. São Paulo: Editora SENAC, 2002.

ZHOURI, A; OLIVEIRA, R. Paisagens Industriais e Desterritorialização de Populações Locais: conflitos socioambientais em projetos hidrelétricos. In: ZHOURI, A.; LASCHEFSKI, K.; PEREIRA, D. B (Orgs.). A Insustentável Leveza da Política Ambiental - desenvolvimento e conflitos socioambientais. Belo Horizonte: Autêntica, 2005.

ZHOURI, A.; OLIVEIRA, R. Desenvolvimento, conflitos sociais e violência no Brasil Rural: O caso das usinas hidrelétricas. Ambiente e Sociedade, v. 10, n. 2, p. 119-135, 2007.

\section{Artigo recebido em 08/05/2012.}

Artigo aceito em 15/03/2013. 